\title{
Specifying the Right Textiles for an Interior Commercial Project
}

\author{
Dr. Kim Rich Meister* \\ College of Family Consumer Sciences, Furnishings \& Interiors, University of Georgia, USA
}

*Corresponding author: Dr. Kim Rich Meister, College of Family Consumer Sciences, Furnishings \& Interiors, University of Georgia, Athens, Georgia, USA.

Received Date: July 10, 2020

Published Date: July 21, 2020

\begin{abstract}
Due to the advancements in the manufacturing of textiles along with the science behind the process, the durability and use has helped to provide even more options in using textiles in a more creative and colorful application for commercial interiors. With that said, as an interior designer the selection of these textiles can be overwhelming, so utilizing the resources, standards, and testing available to us can help us make and use the selections properly. So, what are the reliable resources and information available to us to specify appropriate textiles for commercial interiors?
\end{abstract}

Keywords: Specifying; Textiles; Interior design; Commercial design; Commercial projects; Hospitality design

Abbreviations: NFPA - National Fire Protection Agency; ASTM - American Society of Testing Materials; VOC - Volatile Organic Compounds; ACT - Association for Contract Textiles

\section{Introduction}

As textiles development continues to evolve, it is challenging as an interior designer to research all the new textiles, fabrics, and materials that can be used in commercial interior spaces. The more educated and the more resources we have available to us, the process of selecting and utilizing these types of finishes will be easier to specify. However, there are several factors involved in evaluating and assessing the textiles that can be used that involve durability, economy, safety, longevity and of course aesthetically. Additionally, the specification of these textiles for commercial interior spaces such as corporate, offices, hotels, restaurants, and even medical facilities, must meet several types of standards and testing to ensure the safety and well-being of the people utilizing these spaces. As interior designers, we are legally responsible for the finishes and furnishings we specify and utilizing resources such as the building codes, life safety codes, and understanding the testing agencies such as American Society of Testing Materials (ASTM), National Fire Protection Agency (NFPA), and Association for Contract Textiles (ACT), can help secure the selection of proper textiles.

\section{Discussion}

For commercial interior projects, an interior designer has to have a broad knowledge of textiles in order to evaluate and select the proper materials for the project. Additionally, an overall understanding of the testing and building codes involved is necessary in order to protect the safety and well-being of whom we, as interior designers, design. All commercial projects require that the textiles used are at least fire resistant to help deter the spread of the fire and lessen the smoke generated from the product as it burns. There are several tests in which materials are subjected to in order to assure the textile's integrity. 
As an interior designer, we have to make sure we understand the makeup of the textile and evaluate it based on aesthetics, performance and safety, maintenance, cost, and installation factors [1]. In selecting a textile, aesthetics is vital to the success and theme of the project especially in hospitality design. There are several styles and tastes so having a clear vision of the project and a complete understanding of the client's goals is vital to the success of the project. Aesthetics is a very subjective aspect in design, we all have our personal preferences, but we must select textiles appropriately for the best visual and long-term impact for interior spaces. Once a style is defined, the interior designer can narrow down the colorway and start searching for the appropriate textiles. In addition to selecting textiles that are beautiful and represent the brand or identity of the client, performance and safety is essential in evaluating the material for the determined use.

Life safety, which is based on the occupancy type for a building or space, does have a direct influence on the types of textiles selected due to the mandated testing required to prove the textile may be used in commercial design. Several tests are preformed and have different names and numbers associated depending upon the sources such as National Fire Protection Agency (NFPA), 101 Life Safety Code versus American Society of Testing Materials (ASTM). Many states have adopted California Technical Bulletin 133, or CAL 133, for flammability standards. Since building codes are mandatory, designers are legally responsible for selecting materials that comply even for a customer's own material (COM) [1]. For example, NFPA 101 Life Safety will reference NFPA 701 for vertical flame test and ASTM's test, which is the same, is ASTM D6413 (Figures 1 \& 2). Since Exit and Access to Exits require the strictest ratings of Pass/Fail, even with sprinklers, the textile selected and used in those areas must meet testing guidelines or it cannot be used. Below are two reference guides for understanding which test is used for each specific material from Chapter 10, Finishes and Furniture Selection from The Codes Guidebook for Interiors by Sharon Harmon \& Katherine Kennon, which is very helpful when learning about textile selection for commercial projects [2].

Figure 1: Typical finishes \& furniture tests [2].
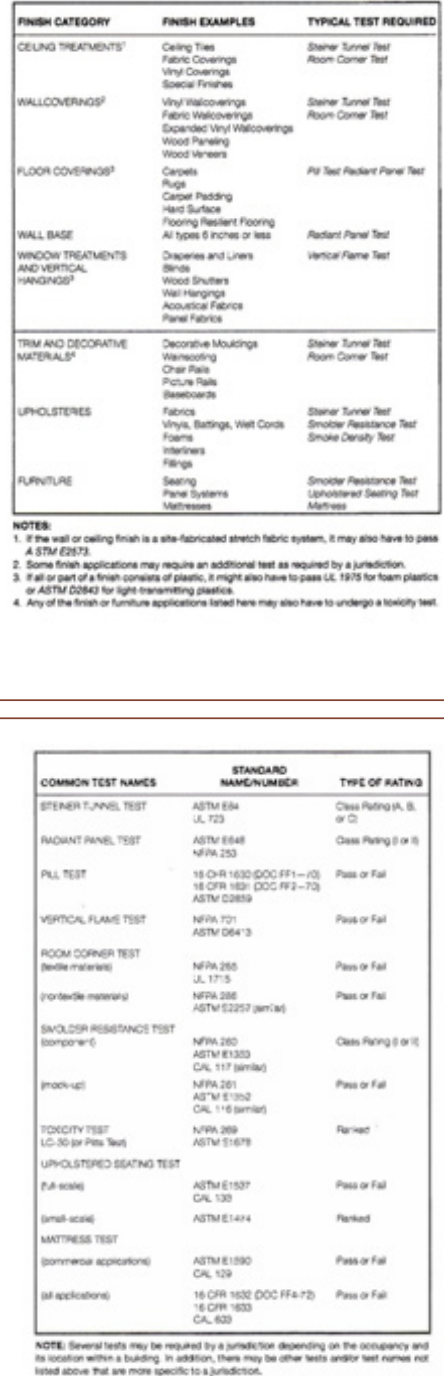

Figure 2: Summary of tests for finishes \& furniture [2]. 
Additionally, this is a great resource for interior designers because we typically write our own specifications for each material selected and must include the testing information, warranty, and installation information necessary to assure that the materials selected are used according to the standards set for those products. For a design project in hospitality, the textile finishes selected are wall coverings including fabrics, upholstery, draperies, and fabrics for accessories such as pillows or soft furnishings and decorative panels. All of these have to meet stringent testing in order to be used in a commercial project. These types of materials or finishes have to be maintained, so durability, especially in high traffic areas, is vital.

Evaluating and specifying a finish such as wall covering for high traffic areas must be extremely durable and resistant to tears, marks, and hand cleaning products. Easy maintenance in cleaning will help ensure the aesthetics of the space for several years to come. Other factors will need to be considered such as the appearance retention, durability and wear-life, and structural stability just to name a few. For appearance retention, color texture, resistance to soiling, snagging and shedding are necessary for a successful finish. As for durability, abrasion resistance, tear resistance and dimensional stability and fuzzing are other factors used to evaluate the finish material. Evaluating structural stability is necessary so that the material does not delaminate, the stability of the yarn, and the tuft binding strength all help define the integrity of the material. Besides being flame resistant, the design and performance should contain low volatile organic compounds, or VOC's, for indoor air quality, and have strong colorfastness, wear resistance, and offer acoustical value, and minimize static within the interior spaces [1]. There are several components involved in selecting the right finishes and materials for an interior project that it can be overwhelming, so utilizing several resources as mentioned above and the Association for Contract Textiles will save time and frustration for design professionals.

Another resource available to designers and other professionals is the Association for Contract Textiles, or ACT, based out of Fort Worth, Texas, and their guidelines or standards for specifying textiles is very helpful and educational. ACT formed back in the 1980s to communicate voluntary guidelines and visual cues for textile selection. These guidelines involve icons to quickly identify the attributes of the textiles such as Physical Properties, Dry and Wet Crocking, Flammability, Colorfastness to Light, and Abrasion, in Low and in High Traffic areas. Each has their own criteria in which the textile must meet in order to receive the designated icon on the label. These visual icons help speed up the selection process as you learn what to look for during the selection of materials. These voluntary standards are completely separate from the building code and life safety requirements, so selecting the textiles with the appropriate testing is required for a commercial interior project [3].
For the flammability standards, the types of textiles tested are woven, coated, and knit and must meet these guidelines in order to be specified for a commercial interior project. The icon designated resembles a flame so if you see this symbol on the back of the fabric memo then you know it meets the flammability testing and this information can be added to the specification. Additionally, the NFPA and ASTM test information is included. For Wet/Dry Crocking test the dye/color transfer from one material to another through rubbing. It is a graded system for both solids and prints, and an artist palette symbol is used as an indicator on the label. For Colorfastness to Light, a sun icon is used, and this test measures the fading of the color due to light exposure. This test also uses a grading system so Grade 1 means the material has a high degree of fading, versus a Grade 5, with no fading. For selecting a textile that is exposed to both natural and artificial light majority of the time this test offers more insight to that material, so use will have to be considered like seating or a wall treatment near windows. For the Physical Properties the icon looks like a star made of fibers and tests the overall durability of a fabric based on its construction. Pilling, Breaking Strength, and Seam Slippage are tested to explore the durability of the material especially for materials used for seating. Many of these tests reference the American Society of Testing Materials (ASTM) so there is a correlation to the standards set that aides in selecting the appropriate materials. For Abrasion, there are two levels, Low Traffic, designated with a lower case "a" and is for private spaces; and High Traffic, designated with a capital "A," and is for public spaces. These standards only apply to the woven and knit fabrics and use two specific testing methods, Wyzenbeek and Martindale. Both tests incorporate the rubbing back and forth with various types of abradants and the sample is abraded at 5,000 double rubs per hour. A fabric that can handle 15,000 double rubs is considered good. The Martindale method is similar to the Wyzenbeek but tests fabrics that have a pile depth less than .08 inches (2mm) and 20,000 double rubs is considered good. For public spaces, the abrasion test has a higher standard of 30,000 to 40,000 double rubs or a higher for a more quality fabric. Thanks to ACT, their rating system standards is a very helpful in understanding the quality and durability of a fabric that is being used for seating and furniture that interior designers can specify. Their website is open to anyone to reference about the durability and performance of a textile at www.contracttextiles.org [3]. Another aspect of evaluating a textile is the cost of the material and the life cycle of that material, which are essential in explaining the cost and quality of a material to the client.

There are two parts in assessing the cost of a material, one is the initial cost and the second is the life-cycle costs of the material being specified. The initial cost includes the actual cost of the material and the installation costs such as preparation, labor, and any accessories necessary. Life-cycle costs include maintenance using cleaning products and the labor to maintain the material or finish. Warranty, energy, and disposal costs are also part of the life- 
cycle cost of the fabric or material [1]. Additionally, the life span of the material must be considered since some may be amortized, especially furniture that is expected to last ten years verses five years. Evaluating the initial cost verses long term can be a bonus in specifying a more expensive material or textile if it is going to last longer. Typically, in commercial public spaces, remodel and renovations are every eight to ten years and a budget is allocated for those updates through the facilities department. Understanding the costs involved in the selection of the materials for a project is essential for the best aesthetic design solution that meets the client's goals.

\section{Conclusion}

Understanding that all of these components are just a brief explanation of what is available to design professionals. Working with the textile showrooms and manufacturer representatives are other sources that designers rely on to help find the appropriate material that meets several of the parameters mentioned above in order to have a successful design solution. However, researching the building codes, life safety codes and exploring the parameters of aesthetics, performance and safety, maintenance, and cost factors to ensure that the designer is making the right choice in textile finishes is paramount to the success of the design. Each of these parameters have their own level of assessment and it can be exhausting to determine the best material. Through this article, the topics discussed can help design professionals with the selection process of textiles specified for commercial interiors.

\section{Acknowledgement}

None.

\section{Conflict of Interest}

None.

\section{References}

1. Willbanks A, Oxford N, Miller D (2015) Textiles for Residential and Commercial Interiors, (4 $4^{\text {th }}$ edn), Bloomsbury Publishing Inc, 1385 Broadway, New York, USA, pp. 28-32.

2. Kennon K, Harmon S, (2018) Chapter 10 Finish and Furniture Selection, The Codes Guidebook for Interiors ( $7^{\text {th }}$ edn), John Wiley \& Sons, Inc., Hoboken, New Jersey, USA, pp. 396-397.

3. (2020) Association for Contract Textiles, ACT, Guide to Textile Specification, pp. 1-4. 